\title{
Research on Construction Process of Steel Box Girder Bridge and Its Stress Analysis
}

\author{
Cheng Kang \\ Sichuan College of Architectural Technology, Deyang, Sichuan, 618000, China
}

\begin{abstract}
The paper introduced the construction method of large segment hosting and its difficulty, and drawing up the corresponding plan of liner and stress monitoring. The paper gives the calculation method of shear area for such a big cantilever thin-walled steel box girder section, namely the shear coefficient computation theory of Professor Hu Haichang, and the use of this shear area perfect beam element model, structure model and the experiment prove that the shell model is more consistent, given a certain reference for similar section project..
\end{abstract}

Keywords-construction control; long-span; steel box continuous girder; large segment hosting.

\section{INSTRUCTION}

Continuous steel box girder bridge has the advantages of large bending stiffness, torsional stiffness, but also has high strength steel structure, light weight, large span capacity, short construction period and other advantages, and the appearance is beautiful, so more and more attention. Large segment hoisting construction technology due to the flexible, high construction efficiency, along with the development of construction technology and the application of more and more. With the continuous steel box girder span increasing, manufacturing technology, positioning technology, linear control requirements increase, the difficulty of construction is more and more big, the control process of bridge construction is more important.

\section{THE COMPOSITION OF THE STEEL BOX GIRDER}

Steel box girder is mainly composed of a top plate, bottom plate, inclined bottom plate, side in web, web and diaphragm and transverse help plate. In order to ensure the pavement thickness of bridge deck on the roof the comply with the design requirements, and keep the flush, take the form of the upper edge of the alignment of the bridge deck roof butt joint of the beam section with different thickness. The main structure schematic diagram is as shown in fig.12.

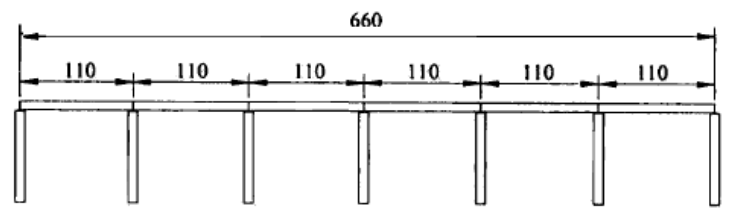

Figure 1. Schematic diagram of steel box girder with six span one coupling arrangement (unit: $\mathrm{m}$ )

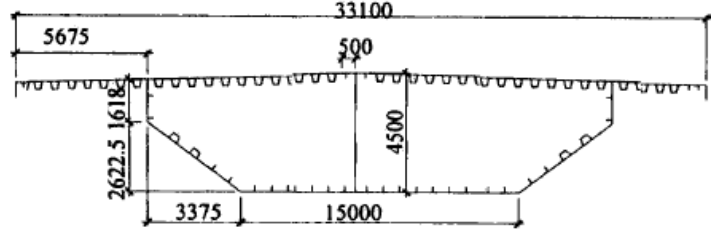

Figure 2. Schematic diagram of steel box girder cross-section (unit: mm)

The roof use four kinds of different thickness $(18 \mathrm{~mm}$, $20 \mathrm{~mm}, 22 \mathrm{~mm}, 24 \mathrm{~mm}$ ) in different sections along the bridge, mainly uses the $U$ rib; the bottom plate adopts five kinds of different thickness(14mm, 16mm, 20mm, 24mm, 28mm) in different sections along the bridge to help, using plate stiffening; inclined bottom plate by using $16 \mathrm{~mm}, 20 \mathrm{~mm}$, $22 \mathrm{~mm}$ with three different thicknesses to different segments in along the bridge, using $U$ steel plate can help and stiffening; web use $20 \mathrm{~mm}, 22 \mathrm{~mm}, 24 \mathrm{~mm}$ three kinds of different thickness in different sections along the bridge to help, using plate stiffening; edge web using $20 \mathrm{~mm}, 22 \mathrm{~mm}$ two kinds of different thickness in different sections along to bridge, using the board help stiffening; three horizontal help plate is arranged between the $10 \mathrm{~m}$ two standard spacing diaphragm.

Construction conditions use the factory prefabricated, span by span large segment hoisting construction scheme. Beam joints between the segments is in the middle pier top side $23 \mathrm{~m}$, the first cross hanging beam length is $132.6 \mathrm{~m}$, the middle span hoisting length is $110 \mathrm{~m}$, tail length is $87 \mathrm{~m}$ cross hoisting. Cross and tail span installation beam segment using the beam end bracket is hung on the front of a provisional cantilever beam end, to meet the design requirements after the welding together.

\section{STEEL GIRDER HOISTING PROCESS}

Manufacture of steel box girder is divided into 3 stages: plate unit manufacturing, bar section making and segmental assembling, these stages are completed in the factory. Large segment production is completed, by the floating crane will beam segment hoisting to transport ship, and transported to the bridge site installation, by lifting scheme across large segment, segment division is determined according to the bending moment of zero position, division of hoisting construction segment is as shown in fig.3. 


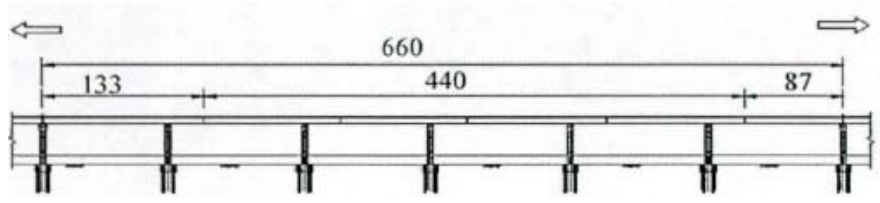

Figure 3. The partition layout of construction segment (unit: m)

Hoisting erection scheme for general construction sequence is as shown in fig.4:

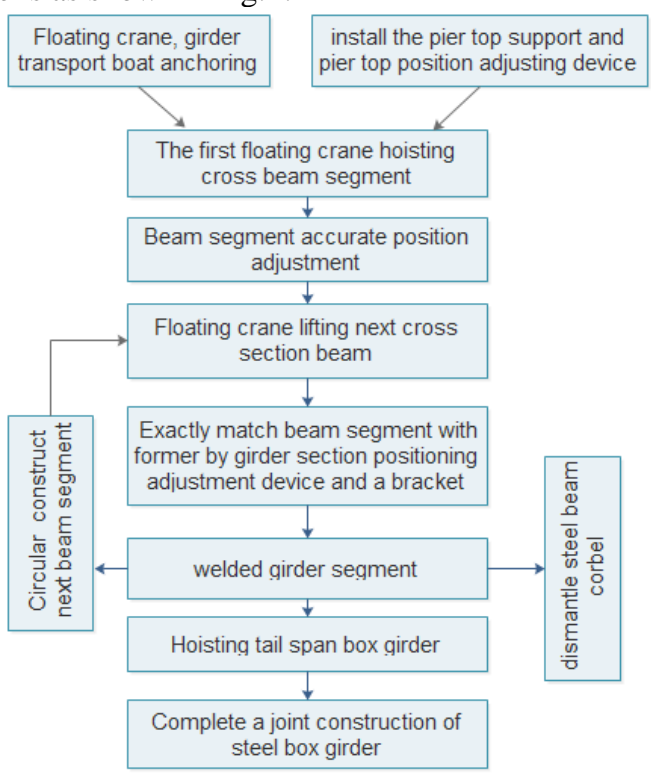

Figure 4. Flow chart of steel box girder construction

When large segment steel box girder hoisting, in addition to each first large segments of steel box girder support in two main piers, the rest of the girder end support in the main piers, the other end place on the beam section (namely: setting up support between beam segments,) to be installed on corbel in the beam segment interface of the roof, setting the temporary support in the roof beam section at the interface has been put in place, lifting bracket lapped on the temporary support, which can play the role of supporting and precision adjustment. Temporary support setting and support system conversion time offset of the support set plays a decisive role, must be a reasonable choice. Hoisting schematic diagram is as shown in fig.5. 6xll0m six span steel box continuous girder bridge hoisting concrete construction + system conversion process is shown in tab.1.

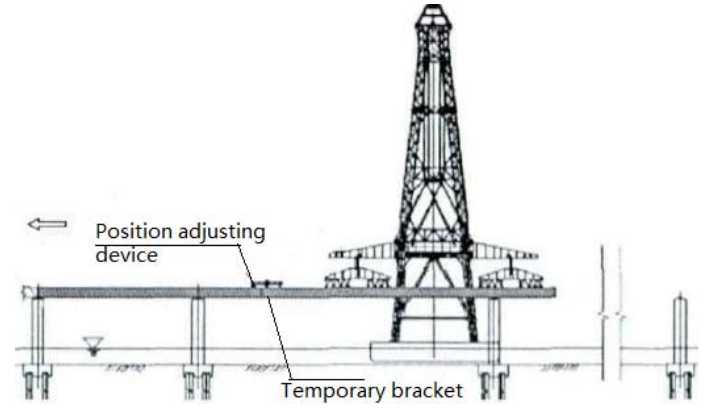

Figure 5. Standard cross lifting adjusting diagram

TABLE.I. THE HOISTING PROCESS

\begin{tabular}{r|l|r|l}
\hline $\mathrm{N}$ & Condition description & $\mathrm{N}$ & Condition description \\
\hline 1 & Lifting the first cross & 11 & Converting the first pier system \\
\hline 2 & Hoisting 2\# span & 12 & Hoisting 5\# span \\
\hline 3 & Welding 1-2 span & 13 & Welding 4-5 span \\
\hline 4 & Hoisting 3\# span & 14 & Hoisting 6\# span \\
\hline 5 & Welding 2-3 span & 15 & Welding 5-6 span \\
\hline 6 & Hoisting 4\# span & 16 & Conversion of fifth pier system \\
\hline 7 & Welding 3-4 span & 17 & $\begin{array}{l}\text { Conversion of sixth pier } \\
\text { system }\end{array}$ \\
\hline 8 & $\begin{array}{l}\text { Conversion of fourth } \\
\text { pier system }\end{array}$ & 18 & $\begin{array}{l}\text { Conversion of seventh pier } \\
\text { system }\end{array}$ \\
\hline 9 & $\begin{array}{l}\text { Conversion of third pier } \\
\text { system }\end{array}$ & 19 & $\begin{array}{l}\text { The two stage of dead load } \\
\text { pavement }\end{array}$ \\
\hline 10 & $\begin{array}{l}\text { Conversion of second } \\
\text { pier system }\end{array}$ & 20 & Bridge \\
\hline
\end{tabular}

\section{STRESS ANALYSIS OF LARGE SPAN CONTINUOUS STEEL BOX GIRDER STRUCTURE}

According to the Timoshenko theory of deep beam, under the action of bending moment, shear beam under bending moment, will produce the deflection y2, will produce an additional deflection y1 shear forces, vertical mutual sliding between the two adjacent sections of each other, y1 did not induce the longitudinal displacement of beam. Literature [4] derived uniformly distributed load and cross section deflection of simply supported beam under a concentrated load.

Under uniform load:

$$
W=\frac{5 q L^{4}}{384 E I} \times\left(1+\frac{48 E I}{5 G A L^{2}} K\right)
$$

Cross concentrated load:

$$
W=\frac{P L^{3}}{48 E I} \times\left(1+\frac{12 E I}{G A L^{2}} K\right)
$$

Among them, $\mathrm{A}$ is the cross section area, $\mathrm{K}$ is the stress nonuniformity coefficient.

Because the stress nonuniformity coefficient $K=1 / k$, where $\mathrm{k}$ is the shear correction factor.

Professor Hu Haichang in 1981 presents a shear correction coefficient calculation formula based on the principle of energy ${ }^{[2]}$ : 


$$
\frac{1}{K}=A \iint\left[\left(\frac{\tau_{x y}}{Q}\right)^{2}+\left(\frac{\tau_{x z}}{Q}\right)^{2}\right] d y d z
$$

The distribution formula of Jourawski shear stress:

$$
\tau=\frac{Q S}{I b}
$$

Take (4) into (3), available shear correction coefficient formula:

$$
K=\frac{I^{2}}{A \int \frac{S^{2}}{b^{2}} d A}
$$

Finally, the shear correction factor for sections:

$$
K=\frac{I^{2}}{A \times \sum V_{i}}
$$

Through the calculation, the pier top counter force is as shown in tab. 2 in every construction stage. As can be seen, second pier stress is maximum in the process of the construction, the maximum value is $26267.0 \mathrm{kN}$, the construction phase of each pier bearing force maximum value appeared in a cross installation, construction monitoring of process on the condition of each pier reaction support a maximum value should focus on control analysis found that the error correction, timely analysis, in order to ensure structural safety, in the whole process of construction reasonable stress.

TABLE.II. THE PIER TOP COUNTER FORCE VALUE IN EACH CONSTRUCTION STAGE (UNIT: KN)

\begin{tabular}{l|c|c|c|c|c|c|c}
\hline Construction & 1 pier & 2 pier & 3 pier & 4 pier & 5 pier & 6 pier & 7 pier \\
\hline Install 1\# & 11004.4 & 17133.4 & $/$ & $/$ & $/$ & $/$ & $/$ \\
\hline Install 2\# & 9512.4 & 26267.0 & 14400.0 & $/$ & $/$ & $/$ & $/$ \\
\hline Install 3\# & 9917.0 & 24010.4 & 23684.8 & 14212.4 & $/$ & $/$ & $/$ \\
\hline Install 4\# & 9822.2 & 24448.8 & 21322.0 & 23644.9 & 14212.4 & $/$ & $/$ \\
\hline Install 5\# & 9849.0 & 24290.2 & 21779.0 & 21042.0 & 23644.9 & 15169.2 & $/$ \\
\hline Install 6\# & 9840.4 & 24338.4 & 21583.2 & 21761.4 & 21042.0 & 25769.4 & 9283.6 \\
\hline Bridge & 12372.0 & 31984.6 & 28152.8 & 28493.6 & 27398.6 & 33154.6 & 11929.0 \\
\hline $\begin{array}{c}\text { Maximum } \\
\text { value }\end{array}$ & 11004.4 & 26267.0 & 23684.8 & 23487.8 & 23644.9 & 25769.4 & 9283.6 \\
\hline
\end{tabular}

(1) The longitudinal deformation

Shear deformation under the condition of the junction structure deformation is as shown in Fig.6, the maximum deformation of steel box girder hoisting appear at first cross, the maximum value is $28.12 \mathrm{~cm}$, appeared in the mid span steel box girder; under the action of live load maximum this value is $7.76 \mathrm{~cm}$, appear on both sides of midspan.

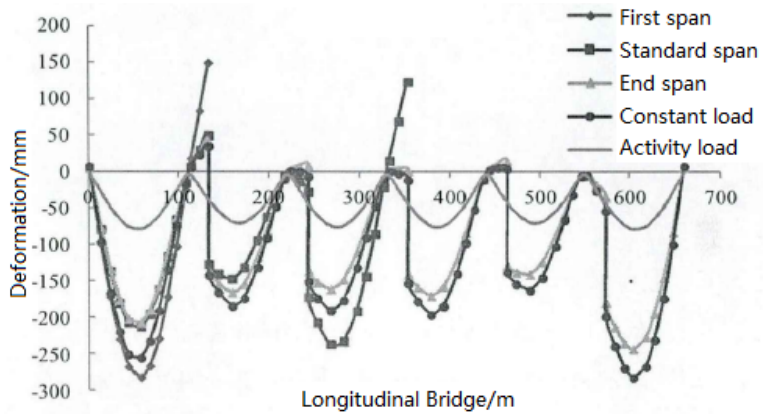

Figure 6. The working pieces deformation map

Calculation results of stress:

Under the condition of the structure stress situation is as shown in Fig.7-8, the maximum stress is126.7MPa at steel box girder for first cross hoisting; the steel box girder stress amplitude is $-31.3 \mathrm{MPa}-42.3 \mathrm{MPa}$ under the action of activity load.

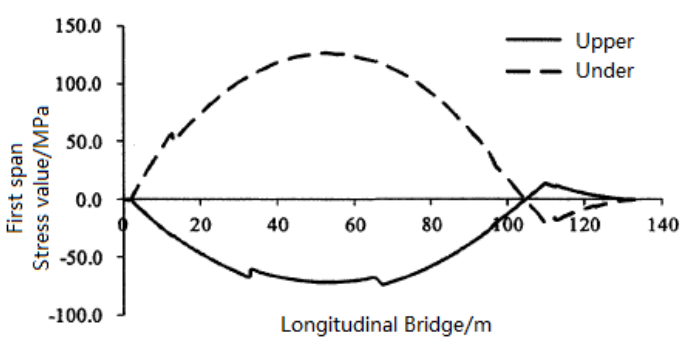

Figure 7. The stress diagram of first cross working hoisting

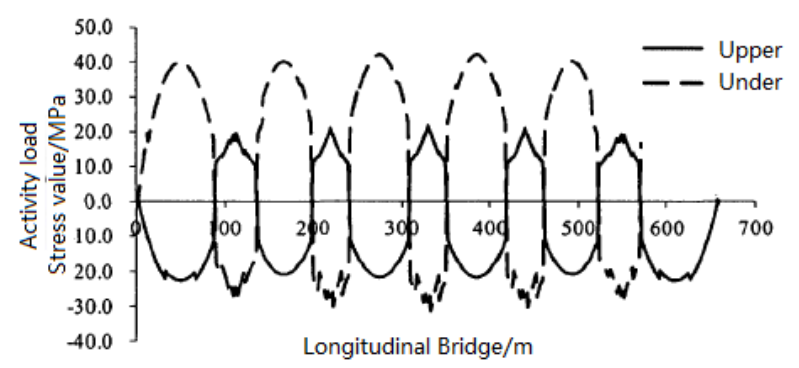

Figure 8. Moving load stress diagram

\section{CONCLUSIONS}

This paper selects the rectangle block method of $\mathrm{Hu}$ Haichang theory to calculate shear correction coefficient calculation. Through the construction of the first cross lifting conditions found that Beam element calculation value using the modified by shear area is close to the true value of deflection of plate and shell element, to verify the reliability calculation of shear correction coefficient method, the method is more effective in this paper. At the same time the data reflects the shear deformation has a non-negligible impact on the bridge. Through the analysis of the data shows that, when considering the shear deformation effect, each span in the cumulative deformation value compared with and without consideration of shearing, deflection increased 
$10 \%$ 20\%, which cannot be ignored. And then used to simulate the construction process of the bridge with consideration of shear deformation model, gives the counter force, deformation, stress a result, it give certain reference for the construction control.

\section{REFERENCES}

[1] Zhou Jianlin, Wu Chong. Deformation analysis of large span cablestayed bridge flat steel box girder cantilever assembling section [J]. Bridge construction .2006 (01): 29-31.
[2] Zhao Yingtai, Wang Xufeng. Modern space steel structure sliding construction technology [J]. Progress in steel building structures.2006 (06): 11-14.

[3] Ye Xiaozhi. Research and application of steel structure bridge installation technology [D]. Shandong University, 2012

[4] Zhang Yongtao, Zhou Renzhong, high Jibing. The technique of integral lifting Chongqi bridge large segment [J]. highway.2011 (10): 82-90.

[5] Cai Jianjun, Ji Hui, Shen Ruili. Research on the key technology of erection of steel box girder of large segment in Dagu River channel bridge of Qingdao Bay [J]. Construction technology.2011 (21): 6671. 